\title{
TECHNOLOGICAL IMPACTS ON MARKET ATTITUDES AND BEHAVIORS
}

\author{
Paul Baines, Cranfield University (Corresponding author) \\ E: paul.baines@cranfield.ac.uk \\ T.: +44(0)1234 758041
}

Running Head: Technological Impacts on Attitudes and Behaviors

\begin{abstract}
Technology has had a profound effect on twentieth century society and is increasingly changing the nature of the way we live our lives in the twenty first century, particularly, but not solely, through innovations in digital and social media marketing. As media and other technologies change, the question arising concerns how these changes impact on consumers' attitudes and behaviors, and consequently on their lives. In this special edition, nine papers are presented, outlining cutting-edge research exploring how changing technologies affect consumer attitudes, emotions and behaviors in a variety of country settings and industries. In this introductory editorial, the papers are outlined in further detail, with a brief exposition of their contribution.
\end{abstract}

KEYWORDS: attitudes; behavior; technology impacts; emotion 


\section{INTRODUCTION}

It's often considered, at the least an aphorism, at best axiomatic, that the speed of technological change is increasing. Kurzweil (2000) spoke of the 'law of accelerating returns', arguing that a graph of the history of technological change displays exponential properties, i.e. that changes in technology accelerate over time. The best example of this phenomenon is Moore's Law, coined by the co-founder of Intel, Graham Moore, that microchip performance would double every year (later amended to every 2 years) but there are many others. Nevertheless, the speed of change during the industrial revolution, when production morphed from agrarian hand-made production to machine-led industrial production, which began in factories in Britain between 1760 and 1830 and which spread around the world, including in the US and Japan in the $18^{\text {th }}$ and $19^{\text {th }}$ centuries and elsewhere in the $20^{\text {th }}$ century (McCloskey, 1981), must also have been pretty dizzying for both producers and consumers. Innovations such as the steam engine, telegraphy, and television created profound changes in mobility and telecommunications, to name only a couple of important industry examples. Nevertheless, the popular history of innovation sometimes seems to fail to account for the impact that technology had on human consumption psychology, as opposed to how technology impacts on the psychology of workers (researched extensively in industrial psychology), although there were early exceptions which considered both (see for example, Münsterberg, 1913).

Regardless of whether or not the speed of change is truly increasing, there is recognition that its effects can be unsettling. Alvin Toffler, perhaps the world's best known and original futurist, predicted in Future Shock (Toffler, 1970) that the speed of technological change would result in social confusion and the break-down of societal decision-making. He predicted the shift to the information society in which we now live, coining the term 'information overload' (Colville, 2016). Nevertheless, the widespread societal angst that Toffler predicted has not, at least yet, come to pass. Society has shown itself to be remarkably adept at adapting to technological change. This is despite the enormous changes that are likely to occur in the marketing process itself with advances in artificial intelligence, social media, the internet of things, virtual reality, neuromarketing, and data analytics, never mind changes to consumption behavior as a result of sectoral change within the economy including in manufacturing (3D printing), space travel (affordable sub-space flights), automotive (driverless and electric cars), computing (cloud services), the sharing economy, construction and town planning (smart cities), currency (bitcoin and other digital currencies), nanotechnology (nanobots in healthcare) and many more. Liz Landy, the CEO of Ipsos Connect, talks of how virtual reality, for example, could transform the leisure and tourism market (imagine a less expensive trip to Antarctica with a wrap-around headset as opposed to cruising there or flying there (say, via Argentina), property development and management (reducing the need for in-person house viewings) and buying automotives (by presenting cars with different paint colours, seating and so on) (Candy, 2016).

In the twenty-first century, we have already lived through profound change, caused by the development of the internet and the advent of social media. Social media (specifically those services offered by Google, Facebook and Twitter) has revolutionized advertising, marketing promotion and marketing analytics. This, and other internet, technologies have substantially altered the way we do business in new and exciting ways. This issue was therefore set up to provide new psychological perspectives into the practice and theory of how technology interacts with opinions, attitudes, beliefs and behaviors in a variety of markets. 
Whilst the original call for papers attracted many submissions, some suggested topics remain unanswered and still remain un-researched. Researchers might therefore want to develop $\mathrm{PhD}$ topics around these themes for their students or investigate these issues further themselves. These include topics such as the relative importance of public opinion versus consumer opinion as mediated by social media and other digital technologies; how social media marketing campaigns drive the rise of social movements (including consumerist and antiglobalization movements); how rumors and conspiracies against companies and brands disseminate across the internet and other digital technologies and their relative effects; and importantly, given its potentially highly negative effects, how anonymity online affects consumer behavior, including customer behavior in so-called 'dark markets' (such as Alphabay, Silk Road and their ilk). Many of the papers that we received and publish cover areas such as the effects of different forms of advertising, particularly digital advertising, on customer cognitions and behaviors; the psychological effects of being part of brand communities and its relative influence on purchase behavior and differences in attitudes and behaviors of customers using e-commerce and m-commerce platforms.

Inevitably, this special issue scratches the surface of how technological change impacts on market attitudes and behaviors. Our motive therefore is not to try to comprehensively cover such a wide-ranging topic but rather to seek to generate ideas for future research in this important field, and thereby to provide new understanding of how marketing research can contribute to enhancing our understanding of how technological change impacts on consumers.

In the first of nine articles, Claffey and Brady (2017), using structural equation modeling and hierarchical moderated linear regression on a sample of 308 survey respondents, study motivational drivers of consumer engagement with firm-hosted virtual communities, to identify antecedents, influences and outcomes, contributing to our understanding of how virtual communities engage consumers (e.g. to co-create new products). Their study highlights that firms should design their virtual communities to facilitate knowledge sharing, provide social support, deliver an enjoyable and useful experience and to enable consumers to co-create, paying special attention to the need to enhance social bonds between members, particularly as their study shows that, in firm-hosted communities, consumers' affective states act as a moderating influence in the relationship between their cognitive appraisal and participation in, and value co-creation from, the community. From a theoretical perspective, the authors produce an integrated model of motivational factors which contribute to consumer engagement in a firm-hosted virtual community.

The second article also considers the topic on online communities. In this study, Mousavi, Roper and Keeling (2017), who also use structural equation modeling but based on data derived from a sample of 752 US residents who self-identified as current members of online brand communities, investigate the intermediate mechanisms mediating and moderating members' social identity effects on brand commitment, and how this leads to positive wordof-mouth and resistance to negative word-of-mouth, for both posters (i.e. those writing review comments) and lurkers (those not writing any comments). Similar to Claffey and Brady (2017) who also highlight the importance of social bonds and affective states, their study reveals that the affective component of social identity is an important driver of members' commitment to the brand, to talking about the brand positively and to resisting negative comments from others. They suggest that companies can gain a competitive advantage when customers' self-concepts are linked to the community as competitors will find it difficult to replicate such bonds. They suggest companies should provide evidence of 
activity within the community, encourage members to interact, that they should listen to customers and provide high-quality up-to-date information and, importantly, deliver rewards to members for their contribution, regardless of whether they are posters or lurkers. The authors suggest further research is necessary to understand why lurkers do not actively participate in brand communities and how companies might increase their feelings of social identity to engender a greater degree of contribution to the community.

In the third paper, Yam, Russell-Bennett, Foth, \& Mulcahy (2017) undertake qualitative research in Australia to explore how 'serious games' (i.e. games designed with a primary purpose other than entertainment) can be used to achieve socially responsible behaviors, in their case energy efficient behaviors such as washing clothes in cold water, switching off lights and maintaining air-conditioning at the optimal temperature of $24^{\circ} \mathrm{C}$. They draw on interviews with members of low-income households and, importantly, consider the social interplay within the household as its members play the Reduce Your Juice game; a game trialed by the Australian government's Department of Industry and Science as part of its lowincome energy efficiency programme. They highlight how socially responsible behavioral outcomes are driven by the customer experience (e.g. the game encouraged 2 of the 3 intended behaviors), co-location of play (i.e. playing the game whilst in the presence of others), household competition (comparing scores with other household members), incidental learning (learning passively through playing), household psychological contracts (household values on energy saving), transference (the transfer of energy saving knowledge from one household member to another), household affective climate (the game turned the household climate in considering energy efficient behaviors from unpleasant, e.g. reminding children to turn off lights several times, to fun) and household conversations (both within the household and, outside it, with others). Participants indicated that they were more motivated to conduct the socially responsible behavior by positive framing than negative framing.

Whilst the third paper outlines exploratory evidence of the power of positive framing in encouraging behavior for social marketing interventions, in the fourth paper, Manika, Gregory-Smith and Antonetti (2017) provide some quantitative evidence of the use of positive reinforcement in achieving behavioral change (via pride). They examine the positive and negative effects of hubristic pride (pride based on self-identity as opposed to the authentic pride felt as a result of personal achievements) on consumers' attitudes and selfregulatory behavior. The study uses an experiment embedded within a Qualtrics Consumer Panel survey of 266 respondents and analysis using structural equation modeling to examine how participants respond to webpages on 'eating heathily' and 'losing weight' on the UK's National Health Service weight control website. They find that pride increases as a result of being exposed to a technology-based weight control intervention, confirming the relevance of eliciting positive emotions in encouraging behavior change. However, they also find that pride has both positive effects on attitudes toward website information (because pride leads to behavioral intentions to control weight through a positive effect on attitudes towards the website information) and negative effects on website interactivity (pride decreases interactivity perceptions, potentially stopping consumers from reading the website). This indicates that pride elicitation has a dual effect and can be counterproductive if the mechanism to elicit pride to encourage a particular behavior also invokes the identity of the consumer. The authors also note that while pride affected behavioral intention to download a mobile health application, it did not directly affect intentions to control weight, demonstrating the need for further research in the field. 
In the fifth paper, Dilmperi, King and Dennis (2017) report on a study conducted in the UK and Greece with 511 respondents to identify antecedents of consumers' attitudes and intentions to acquire music both legally and illegally using the framework of the Theory of Planned Behavior. Music piracy is a major problem for the music industry, given it is constantly evolving via new platforms including Tumblr, Twitter, BitTorent, unlicensed cyberlockers and other channels. The authors conclude that perceived quality of music is the most significant factor affecting consumers' attitudes towards music acquisition when purchasing legally and perceived benefits of piracy (e.g. convenience, speed, cost) the most significant factor affecting consumers' attitudes towards music acquisition when purchasing illegally via street vendors and peer to peer channels. This suggests that music companies might need to bundle other items (such as free memorabilia) with music products. A further important finding concerns the fact that those who idolise their fans the most prefer to buy their idols' music legally, suggesting that music companies and their artists work hard to build relationships with their fans. However, idolatry also had a positive impact for some fans to acquire music illegally through peer to peer platforms. The authors indicate that there are numerous important implications including: that there is no widespread belief that piracy is criminal, that there is a need to tighten regulations on piracy, increase sanctions and publicise the imposition of penalties and that artists/idols should be used as spokespeople in campaigns to promote the negative effects of illegally acquiring music.

In the sixth paper, Stathopoulou, Borel, Christodoulides and West (2017) use a two step qualitative-quantitative methodological approach to examine the effects of creativity on consumer branded hashtag engagement in TV advertising using 15 depth interviews, two different ad appeals (humor vs. warmth) and an online survey sample of 259 participants. Their results indicate that original, unusual, relevant, appropriate advertisements incorporating hashtags are more likely to generate consumer engagement except where the participant is already familiar with the brand, where relevant and appropriate advertisements lead to less hashtag engagement. They suggest advertisers incorporating hashtags should design their ads to grab attention, be aimed at those familiar with the brand, and should use the warmth appeal (since it leads to greater sharing).

In the seventh paper, Auschaitrakul and Mukherjee (2017), using three experimental studies based on Mturk participants, show how online display advertising is more effective in terms of attitudes towards the ad and the brand when appearing on commercial websites (e.g. Amazon and Walmart) rather than when appearing on social media websites (e.g. Facebook and LinkedIn) due to perceived fit-fluency. Importantly, the authors suggest that advertising buyers should be more sceptical of the effectiveness of advertising on social media websites as a consequence.

In the eighth paper, Chung and Cho (2017) discuss the underlying mechanisms through which social media use affect celebrity endorsement, using data collected from 400 Korean Wave fans (i.e. people interested in Korean culture including films, popstars etc.) in Singapore via an online survey. Using structural equation modeling, they found that parasocial interactions (i.e. online interactions through social media between fans and their celebrity icons) have a positive impact on celebrity endorsement processes. Parasocial relationships mediated the relationships between social media interactions and source trustworthiness, social media interactions influenced parasocial relationships through selfdisclosure and source trustworthiness positively affected brand credibility which heightened purchase intention. They find that the technological characteristics of new media have altered 
consumer-celebrity interactions, creating more interactive, complex and dynamic relationships than occurred in the conventional advertising of the past.

In the final paper, Obeidat, Xiao, Iyer and Nicholson (2017) conclude the special issue with a mixed method study looking at how service failure types impact on consumers' primary and secondary appraisal processes which in turn lead to consumer revenge intentions in the UK and Jordan. First they conduct depth interviews to explore online consumer revenge and typify service failure into process and outcome failures, and then they used online surveys with 200 respondents each in the UK and Jordan respectively, and confirmatory factor analysis and structural equation modeling to analyze the results. The authors find that outcome failures are perceived as more severe than process failures and propose that cognitive appraisal theory requires extension to explain the process that revenge actors go through in contemplating their actions through online channels. They suggest that firms should be compassionate in considering how consumers have actually been, and perceived to have been, harmed, be quick to redress actions to head-off potential revenge drives and be prepared to develop a capability to undertake social media monitoring to spot these situations when they arise.

As a collected work, these articles provide us with a strong understanding of how attitudes, motivations, and behavior are affected in a variety of online scenarios, both in conventional and social marketing situations, including in online communities, mobile gaming, technology-based health interventions, in legal/illegal music acquisition, in online display advertising, in online celebrity endorsement, and in online consumer revenge situations.

We would like to thank everyone who worked hard to bring this special edition to fruition. We had over 45 high-quality papers submitted by scholars from around 16 countries. Our final selection of papers reflect studies conducted by researchers from the US, Ireland, UK, Jordan, Singapore, Canada, Thailand and Australia based on data collected in these countries and in Greece. We would like to thank everyone who took the time to develop and submit their paper. The degree of interest received illustrates the pressing importance of technological change on the marketing discipline in general and on market attitudes and customer behavior in particular. However, it was not possible to publish all the papers received and so it was necessary to be selective in making the final selection of manuscripts for publication. We would like to thank the authors for their patience during the review process, especially when we were encouraging them to improve their manuscripts through various rounds of review. We would particularly like to thank the reviewers for their efforts in bringing about this special edition; their critical and appreciative comments helped improve the authors' work. We would like to thank Sue Gregory in the Demand Chain Management community at Cranfield University for her sterling work in administering the review process.

In addition to the labor put in by the authors and reviewers in this issue, the guest editor would also like to thank the Executive Editor of Psychology \& Marketing, Rajan Nataraajan, for his excellent support, great guidance and thoughtful input at many points in the design, development and production phases of this special edition; without him this special edition would of course never have come to pass, but he has also contributed enormously to improving the quality of the final selection of papers. 


\section{REVIEWERS}

Paolo Antonetti, School of Business and Management, Queen Mary, University of London, UK.

Diederich Bakker, Hanze University of Applied Sciences Groningen, The Netherlands.

Kerrie Bertele, Hertfordshire Business School, University of Hertfordshire, UK.

Mairead Brady, School of Business, Trinity College Dublin, Republic of Ireland.

Ross Brennan, Hertfordshire Business School, University of Hertfordshire, UK.

Ethel Claffey, School of Business, Waterford Institute of Technology, Republic of Ireland.

Benedetta Crisafulli, Cranfield School of Management, Cranfield University, UK.

Wojciech Cwalina, Warsaw School of Social Psychology, University of Social Sciences and Humanities, Poland.

Charles Dennis, Middlesex University Business School, Middlesex University, UK.

Francesca Dall'Olmo Riley, Kingston Business School, Kingston University, UK.

Dianne Dean, Hull University Business School, University of Hull, UK.

Janine Dermody, Oxford Brookes University Business School, Oxford Brookes University, UK.

Athina Dilmperi, Middlesex University Business School, Middlesex University, UK.

Radu Dimitriu, Cranfield School of Management, Cranfield University, UK.

Angela Dobele, The School of Economics, Finance and Marketing, RMIT University, Australia.

John Egan, Regent's Business School London, Regents University, UK.

Fiona Ellis Chadwick, School of Business and Economics, Loughborough University, UK.

Andrzej Falkowski, Warsaw School of Social Psychology, University of Social Sciences and Humanities, Poland.

Chris Hand, Kingston Business School, Kingston University, UK.

Robert Hooker, Muma College of Business, University of South Florida, USA.

Shailendra Pratap Jain, Foster School of Business, University of Washington, USA.

Tamira King, Cranfield School of Management, Cranfield University, UK.

Anvita Kumar, Coventry Business School, Coventry University, UK.

Ming Lim, School of Business, University of Leicester, UK.

Jenny Lloyd, School of Economics, Finance and Management, University of Bristol, UK.

Emma Macdonald, Cranfield School of Management, Cranfield University, UK.

Stan Maklan, Cranfield School of Management, Cranfield University, UK.

Danae Manika, School of Business and Management, Queen Mary, University of London, UK.

Frauke Mattison Thompson, School of Management and Business, Kings College London.

Nina Michaelidou, School of Business and Economics, Loughborough University, UK.

Paul Morrissey, School of Business, Waterford Institute of Technology, Republic of Ireland.

Aron O'Cass, Tasmanian School of Business and Economics, University of Tasmania,

Australia.

Robert Ormrod, Department of Management, Aarhus University, Denmark.

Kelly Page, Live What You Love LLC, Chicago, USA

Stuart Roper, Bradford University Management School, Bradford University, UK.

Michael Saren, School of Business, University of Leicester, UK.

Ann Torres, J.E. Cairnes School of Business and Economics, NUI Galway, Republic of Ireland.

Peter Trim, Department of Management, Birkbeck College, University of London, UK, Julia Wolny, Southampton Business School, University of Southampton, UK. 


\section{REFERENCES}

Auschaitrakul, S., and Mukherjee, A. (2017). Online display advertising: The influence of website type on advertising effectiveness. Psychology \& Marketing, forthcoming.

Candy, L. (2016). Plunge. Applied Thinking 2017 (Campaign magazine supplement), 11 November, 10.

Chung, S., \& Cho, H. (2017). Fostering parasocial relationships with celebrities on social media: Implications for celebrity endorsement. Psychology \& Marketing, forthcoming.

Claffey, E., and Brady, M. (2017). Examining consumers' motivations to engage in firmhosted virtual communities. Psychology \& Marketing, forthcoming.

Colville, R. (2016). Alvin Toffler obituary. The Guardian, 3 July. Retrieved 12 November 2016, from: https://www.theguardian.com/society/2016/jul/03/alvin-toffler-obituary.

Dilmperi, A., King, T., \& Dennis, C. (2017). Towards a framework for identifying attitudes and intentions to music acquisition from legal and illegal channels. Psychology \& Marketing, forthcoming.

Kurzweil, R. (2000). The age of spiritual machines: When computers exceed human intelligence. London: Penguin.

Manika, D., Gregory-Smith, D., \& Antonetti, P. (2017). Pride in technology-based health interventions: A double-edged sword. Psychology \& Marketing, forthcoming.

McCloskey, D. N. (1981). The industrial revolution, 1780-1860: A survey. In R. Floud and D.N. McCloskey (Eds.). The economic history of Britain, 1700-present, 1, 103-127.

Mousavi, S., Roper, S., and Keeling, K. (2017). Interpreting social identity in online brand communities: Considering posters and lurkers. Psychology \& Marketing, forthcoming.

Munsterberg, H. (1913). Psychology and industrial efficiency. Boston: Houghton Mifflin.

Obeidat, Z.M.I., Xiao, S.H., Iyer, G., \& Nicholson, M. (2017). Consumer revenge using online and social media: An examination of the role of service failure types and cognitive appraisal processes. Psychology \& Marketing, forthcoming.

Stathopoulou, A., Borel, L., Christodoulides, G., \& West, D. (2017). Consumer branded \#hashtag engagement: Can creativity in TV advertising influence hashtag engagement? Psychology \& Marketing, forthcoming.

Toffler, A. (1970). Future shock. London: Random House.

Yam, A., Russell-Bennett, R., Foth, M., \& Mulcahy, R. (2017). How does serious m-game technology encourage low-income households to perform socially responsible behaviors? Psychology \& Marketing, forthcoming.

Correspondence regarding this article should be sent to: Paul Baines, Centre for Strategic Marketing and Sales, Cranfield School of Management, Cranfield University, College Road, Cranfield, Bedfordshire, MK43 0AL, United Kingdom (paul.baines@ cranfield.ac.uk). 